\title{
Modelo para la gestión de capital de marca en Internet
}

Vicente Ros Diego. Universidad CEU Cardenal Herrera

Resumen:

El objeto principal del presente trabajo de investigación es proponer un modelo de comunicación y de capital de marca que potencie el valor de marca en Internet. Si se extrapolan los aspectos más importantes para la construcción efectiva de una marca al medio Internet, puede afirmarse que la satisfacción del usuario con el entorno digital, así como la reputación que el medio Internet logra gracias a la integración del usuario con la organización, son los dos factores más importantes para el gestor en comunicación institucional en el escenario digital.

Palabras clave:

Internet, marcas, usuario, interacción, eBranding, publicidad 2.0, marketing

Abstract:

The main object of this work of investigation is the proposal of a model of communication and brand capital that fosters the potential of a brand in the Internet. If the most important aspects for the effective construction of a brand in the Internet are extrapolated, can affirm that the satisfaction of the user with the digital surroundings, as well as the reputation that the average Internet obtains thanks to the integration of the user in the organization, becomes more important factors for the manager in institutional communication in Internet both.

Key Words:

Internet, Branding, User, interaction, eBranding, Advertising 2,0, marketing. 


\section{Introducción}

La revolución de las Tecnologías de la Información y la Comunicación (TIC) se plasma en la transformación de la publicidad. La campaña unidireccional, basada en el concepto de push (empujar el mensaje hacia el consumidor) y orientada a un público pasivo, deja paso a estrategias basadas en el concepto "pull", que tienen como objetivo atraer al consumidor hacia el mensaje. En Internet, un medio tan vital como viral, la marca no puede esperar a su consumidor, tiene que activar su target.

En el mercado actual no cabe hablar de receptores, sino de consumidores que han participado en campañas de tanto éxito como las orquestadas por Dove, Fiat 500, Coca-Cola o Mentos, en las que el cliente asume un papel creador y vive con "sus" marcas. IBM prevé que en 5 años el 15\% de los espots en televisión y el 25\% por ciento de los espots on line serán creados por los usuarios.

El "usuario 2.0" es un consumidor de nueva generación, un experto que decodifica las intenciones de las campañas publicitarias y se revuelve contra el monólogo comunicativo de las grandes compañías. Es el crossumer, concepto desarrollado por The Cocktail Analysis en 2007, un receptor que ha cruzado la línea infranqueable que lo separaba del productor convirtiéndose en emisor real de mensajes, con un compromiso mayor con aquellas marcas que se comprometen con él y con sus amigos. Es, asimismo, un consumidor que está cansado de largos bloques publicitarios y a quien los nuevos medios le dan la oportunidad de crear una nueva relación con ellos. Prueba de ello es el Manifiesto Cluetrain ${ }^{1}$ (Levine, Locke, Searls \& Weinberger, 2000).

Según Bassat (2008), la publicidad on line va a ganar espacio a la televisión en un periodo relativamente corto de tiempo. Entre tanto, como sostiene Moliné (2005), tal es la capacidad de Internet para construir marca y para influir mediante la marca en el éxito de cualquier actividad de marketing que se integra en las demás formas de comunicación.

Los cambios producidos en el escenario de la comunicación publicitaria, unidos a los datos de audiencia e inversión publicitaria en Internet hacen ineludible tanto el replanteamiento de las estrategias de comunicación de las empresas como el análisis de la repercusión de Internet en la gestión de marcas de las organizaciones, lo que constituye el objeto de estudio de la presente investigación.

\footnotetext{
"No hay secretos. Las compañías necesitan bajar de su pedestal y hablarle a la gente con quien esperan establecer relaciones. Pero primero, deben pertenecer a una comunidad. Estás invitado, pero es nuestro mundo. Quitate los zapatos y déjalos junto a la puerta. Si quieres comerciar con nosotros, ¡baja de tu camello! Si quieres que te dirijamos la palabra, dinos algo. Que sea algo interesante para variar. Nuestra lealtad es para con nosotros mismos, nuestros amigos, nuestros nuevos aliados y conocidos, hasta nuestros compañeros de batalla. Las empresas que no juegan un papel en este mundo, tampoco tienen futuro".
} 
La marca desempeña un rol estratégico en las organizaciones, por ser el valor añadido con el que se dota a productos y servicios. Como afirma Kotler (2006), este valor se puede reflejar en cómo piensan, sienten y actúan los consumidores respecto a la marca, o en los precios, la cuota de mercado y la rentabilidad que genera la marca para la empresa. En cualquier caso, el capital de marca es un activo intangible basado en la percepción de marca del consumidor. El capital cliente es el sumatorio del capital valor, capital marca y capital relaciones.

Según el Informe anual sobre el Estado de la Publicidad y el Corporate en España y Latinoamérica (Alloza (2001:210), su creación debería estar centrada en: “... conseguir establecer y mantener a lo largo del tiempo la mayor coherencia posible entre las expectativas creadas por la comunicación y la experiencia real de todos los públicos objetivos cuando entran en contacto con la marca”. Los aspectos más importantes para la construcción efectiva de una marca según el citado informe son, por este orden, la satisfacción de los clientes con el producto, la credibilidad y reputación de la organización, la calidad estratégica de comunicación, el volumen de inversión en comunicación y el desarrollo de valores de tipo emocional.

La agencia Young and Rubicam sintetiza el paso de lo tangible a lo intangible en el "brand laddering” un proceso evolutivo que se desarrolla, en cuatro fases: el espacio mental (qué soy en la mente del consumidor, basado en la USP o Unique Selling Proposition), la tangibilización (soy distinto por una serie de beneficios funcionales), el vínculo emocional (qué siente por mí el consumidor, basado en beneficios emocionales que aportan personalidad propia) y, finalmente, el Brand comunity (qué eres si estás conmigo, basado en unos valores que configurarán la esencia de marca).

El branding es el proceso de creación de valor de marca que, según Koetler (2006), debe constituir el eje en la administración estratégica del conjunto total de activos y pasivos vinculados a la marca, al nombre y/o al símbolo que la identifican, lo que influirá en el valor suministrado; el concepto de branding no remite únicamente a la identidad sino también a la entidad propia de una marca.

Teniendo en cuenta lo anteriormente expuesto, gestionar el eBranding debe ir más allá de tener presencia en la Red con un logo más o menos adaptado a una interfaz digital. El look and feel o aspecto gráfico de un site es muy importante, pero sólo es un ingrediente ${ }^{2}$.

2 Según Vallet (2005), “eBranding es, sobre todo, la experiencia del usuario, es cada aspecto de la relación entre la compañía y el usuario en la Red. Los logos y los tagline (eslogan en Internet) son efectivos solo si suman la actitud de una empresa. Soportan la marca, pero no la crean. El eBranding culmina en un símbolo que la gente asocia con él, con una experiencia que tienen con la organización, pero el trabajo duro del eBranding está en crear dicha experiencia. El eBranding es el proceso de transformar un sitio web en una experiencia única para el usuario. Única por la calidad de su diseño, por la utilidad y usabilidad de sus contenidos y por la simple y eficaz lógica funcional en la navegación e interacción con dicho sitio web". 
Los beneficios que reporta el eBranding son tener presencia en el espacio en el que el cliente se informa y toma la decisión de compra, experimentar a bajo coste en mercados emergentes, poseer un top of mind sostenido, desarrollar fidelidad de marca, establecer joint-ventures a la escala de las necesidades de la imagen de marca mediante co-branding, hablar cara a cara con el cliente y crecer en credibilidad, y crear y crecer con el Digital Lifestyle (Vallet, 2005).

\section{Propuesta de modelo de capital de marca para Internet}

El objeto principal del presente trabajo de investigación es desarrollar un modelo de comunicación y de capital de marca que proporcione los descriptores clave en la construcción de marca a través de Internet. Para ello, se lleva a cabo una fase de recopilación y revisión bibliográfica acerca de los temas central y adyacentes del objeto de estudio.

La segunda fase consiste en analizar los diferentes modelos de la teoría de la usabilidad y gestión de marcas, definir y estudiar desde el punto de vista teórico los parámetros considerados clave en comunicación corporativa a través de Internet y finalmente proponer un modelo propio. Se tienen particularmente en cuenta los cuatro modelos de gestión de capital de marca más consolidados (Kotler, 2006: 291):

- Brand Asset Valuator de Young and Rubicam, que reconoce cuatro componentes clave del capital de marca: diferenciación (grado en el que una marca es diferente al resto), relevancia (atractivo de una marca), estima (reputación y satisfacción de las promesas percibidas por el consumidor) y conocimiento (nivel de familiaridad e intimidad de los consumidores con la marca)

- $\quad$ Brand Z, desarrollado por Millward Brown y WPP, basado en el Brand Dynamics: presencia (familiaridad activa en la prueba de la promesa: ¿Conozco la marca?), relevancia (cubre necesidades con precios adecuados: ¿Me ofrece algo?), funcionamiento (correcto funcionamiento del producto: ¿Qué me entrega?), ventaja (basada en atributos emocionales, racionales o de notoriedad: ¿Me ofrece algo mejor que los demás?) y compromiso (vínculos racionales y emocionales: Nada puede superarla)

- $\quad$ Aaker (1991), que identifica cinco categorías de activos y pasivos ligados a una marca: lealtad a la marca, notoriedad, calidad percibida, asociaciones de marca y otros activos propiedad de la marca (patentes, marcas registradas, etc.)

- Modelo de Resonancia de la marca, que considera que la creación de marcas es un proceso ascendente que implica garantizar que los clientes identifiquen la marca, establecer la totalidad del 
significado de la marca en la mente del cliente, provocar respuestas apropiadas del cliente en cuanto

a juicios y opiniones y transformar respuestas para crear una relación intensa y activa de lealtad

En la tercera etapa, y a partir del análisis documental, se desarrolla la investigación empírica, que básicamente se construyó en dos fases: generación de técnicas de evaluación de sitios web y desarrollo de investigación cuantitativa y cualitativa.

Finalmente procedemos a la configuración del modelo y su validación o y en análisis de la información obtenida.

El modelo que se presenta pretende describir cómo se desarrolla el capital de una marca en Internet, y por ende, recoge los parámetros básicos de la comunicación publicitaria en Internet. Este modelo toma como base la satisfacción de los clientes con el producto, y la credibilidad y reputación de la organización (American Marketing Association, 2007).

Tabla I. Proyección de la marca en Internet

\begin{tabular}{|lll|}
\hline Marketing & Construcción de marca & Comunicación corporativa \\
\hline Dirección de relaciones & Satisfacción del usuario on line & Excelencia en gestión de contenido \\
& & (Usabilidad, experiencia del usuario, \\
& flujo) & Estrategia de vínculos \\
& & (Intranet, herramientas eCRM, \\
& fidelización) \\
\hline Creación de valor & Reputación corporativa & Gestión de intangibles \\
& & (branding, valores emocionales \\
& & y sociales) \\
\hline
\end{tabular}

Fuente: Elaboración propia

Gráficamente, la propuesta se expresa en un diagrama piramidal (ver figura 1) cuya cúspide es la unión entre la satisfacción del usuario y la reputación corporativa. El diagrama se divide en dos partes: la gestión de contenido y la gestión de intangibles. Ambas vertientes tienen un punto común, en la cima de la pirámide, cuando la satisfacción del usuario aporta valor para la marca on line. Esto solo será posible cuando se gestionen las 4 F's del marketing interactivo, desarrollando un flujo atractivo con funcionalidad para el usuario y un feedback adecuado que persiga una fidelización final 


\section{Figura 1. Modelo de capital de marca en Internet}

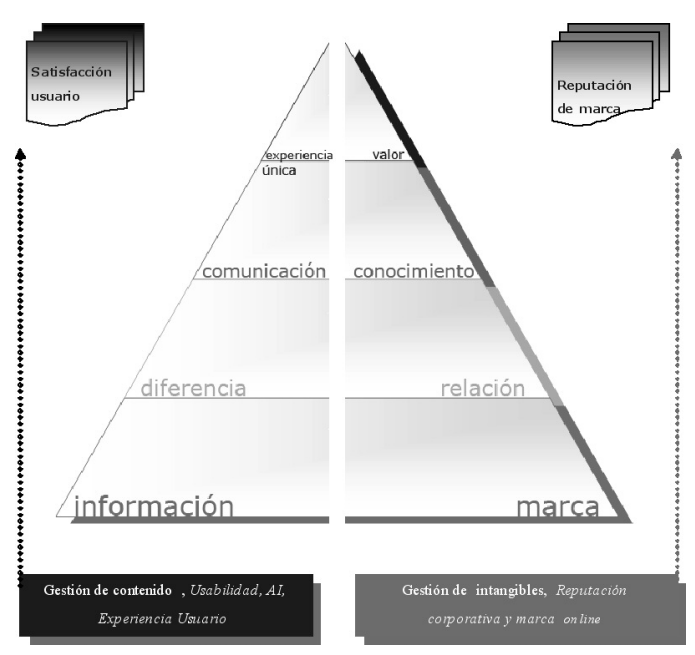

Fuente: Elaboración propia

\subsection{Gestión de la satisfacción del usuario online}

El modelo aborda cuatro variables racionales de construcción de marca on line relacionadas con gestión de contenido y satisfacción de experiencias del usuario: la información, la diferencia, la comunicación y la experiencia única.

\subsubsection{Información}

En esta fase, la clave es la arquitectura de la información: “Encuentro lo que quiero”, es decir, presentar la información hipertextual de manera que el usuario encuentre la información de forma efectiva: "Navego de forma efectiva".

Esta variable de gestión contiene diversas propiedades como accesibilidad, funcionalidad (rapidez, eficacia en búsquedas, enlaces bien definidos), calidad de uso (estructura de información eficiente), adaptación de información al público objetivo y flexibilidad (navegación intuitiva con multiplicidad de vías para llegar al objeto informativo). 


\subsubsection{Diferencia}

La diferenciación de un sitio web es el segundo paso en la gestión del mismo. Tras el estudio de la información y su estructura se analizan los elementos que posibilitan lograr la diferencia del sitio sin olvidar el principio de consistencia por el que toda web debe presentar su información de manera homogénea.

La página web debe estar orientada al usuario y aportar aspectos diferenciales del servicio, creando sensaciones significativas que comprometan creativamente al usuario.

Para ello, hay que desarrollar contenidos de calidad (diferenciales y novedosos), dinamismo (actualización de servicios y contenido), innovación y proactividad (anticipación a necesidades de usuario), y personalización y codificación creativa (con códigos gráficos familiares e intuitivos).

\subsubsection{Comunicación}

El siguiente grado que permite una aproximación al centro del modelo (el usuario) es la comunicación que implica mayor grado de interacción. En este modelo, la comunicación surge con un doble sentido:

- $\quad$ Relación: el modelo permite en todo momento obtener un feedback del usuario, no solo en cuanto a solicitudes formales de información, sino también una retroalimentación que permita obtener información sobre los aspectos de interés para el usuario y el análisis de su navegación por el sitio.

- $\quad$ Participación: tiene una doble vertiente. Por un lado, implica el desarrollo de la competencia mediática del usuario al permitir que este no solo reciba contenidos, sino que además posea la capacidad de contribuir con la creación de contenidos en el web site. Por otro lado, la participación supone un refuerzo de la identidad deseada del público que es quien selecciona las imágenes corporativas creando su imagen real de la organización.

En esta fase del modelo, el proyecto web debe además cumplir un objetivo técnico: el sitio web debe comunicarse en la Red de modo que el usuario se convierta no solo en el sujeto que tiene el control dentro del web site, sino también en público que decide dónde encontrar la página web (buscadores, portales, blogs, $e$-mail, etc.).

Las propiedades de esta tercera variable de gestión son el feedback, la vinculación racional, la conectividad, la participación y la notoriedad en la Red.

\subsubsection{Experiencia única}

El último grado del modelo lleva al desarrollo de una web que permita que el usuario pueda interactuar con ella mediante la posibilidad de comunicarse e intercambiar valores de navegación. Debe lograrse una 
máxima personalización y una aportación de servicios de valor añadido para los diversos públicos de la web que supongan una experiencia única en la navegación.

Hay que tratar de lograr “intercreatividad”, concepto de Tim Berners-Lee (2000: 56), entendida como “... el proceso de hacer cosas o resolver problemas juntos. Si la interactividad no es solo sentarse pasivamente delante de una pantalla, entonces la intercreatividad no es solo sentarse frente a algo interactivo".

Como puede observarse, la intercreatividad supone una suma de dos nociones: creatividad (Csikszentmihalyi, 1998: 35) e interactividad (relación recíproca entre la interfaz y el usuario). Así, la intercreatividad se convierte en una instancia superadora de la interactividad y, por tanto, en un grado máximo de aproximación al centro del modelo (el usuario). Esta interactividad es la base de todo el proceso de creación de marca. De hecho, la segunda ley inmutable de la marca en Internet que propone Ries es la ley de la interactividad: “Sin ella, su sitio web y su marca no irán a ninguna parte” (Ries y Ries, 2000:24).

Al final de este proceso el usuario habrá llegado a una experiencia única, posible gracias al cumplimiento de todas las promesas y a la calidad percibida en todo el proceso. Se pretende que el usuario se identifique con la marca y la haga suya, entonces se conseguirá la pretendida autoimagen.

\subsection{Gestión de la reputación de marca en Internet}

El modelo contempla cuatro intangibles que fomentan la reputación de la marca on line, que remiten a la gestión de la imagen de marca, de la relación, del conocimiento y del valor.

\subsubsection{Imagen de marca}

En esta fase el usuario no solo navega de manera eficiente y se encuentra satisfecho con su proceso de navegación, sino que también puede afirmar que "la relación con la empresa mediante su sitio web es eficaz, me compensan con servicios de valor añadido: son competentes”. Es decir, no encuentra en la web únicamente servicios que espera, sino que estos le aportan determinados valores que permiten configurar una serie de vínculos emocionales entre ambos.

Esto se logra cuando existe identificación (mediante vinculación emocional), personalidad, relevancia y estima (satisfacción con la promesa percibida).

\subsubsection{Relación}

La gestión de la relación implica el análisis de la experiencia óptima del usuario y la del bien común aportado (mediante la interacción, participación e integración de todos los públicos). 
Por tanto, esta variable se representa gráficamente como un peldaño más cercano a la cúspide ya que conlleva el análisis y desarrollo de una serie de actividades relacionadas con la retención del cliente a través del aumento de su lealtad y satisfacción. La relación no solo implica el desarrollo de un feedback continuo, sino también la capacidad de generación de vínculos emocionales y sociales a través de la marca on line.

Las propiedades que proporcionan el objetivo expuesto son el compromiso (mediante vinculación social), la comunicación interna (Intranet), la lealtad, la emoción, la comunidad y la Total Customer Experience (basado en enfoque relacional).

\subsubsection{Conocimiento}

Knowledge Management o gestión del conocimiento implica lograr que la información dentro de una organización llegue a todo aquel que la necesite, procesada de forma tal que sea posible llevarla a la práctica.

Se trata de mejorar no solo el servicio hacia el público, sino también de flexibilizar y mejorar la calidad de los procesos (de aprendizaje) desarrollados por la organización y que necesariamente deben conducir a una mayor personalización del sistema e interacción entre sus miembros.

Las propiedades de esta tercera variable de gestión son la interacción (en procesos de comunicación y de aprendizaje), la cooperación (personalización y trabajo participativo) y la transparencia (comunicación fluida).

\subsubsection{Valor}

El último grado del modelo aborda una gestión de valor que cree elementos diferenciales reales que hagan que el usuario tenga cierta actitud hacia la marca. Esto solo será posible si se aporta algo de valor, es decir, si existe personalización y confianza hacia la marca. Tras conseguir esta actitud, hay que hacer participar al usuario. La participación es el paso que se habrá conseguido cuando el usuario se identifique con la marca, cuando la haga suya, cuando haya detectado beneficios útiles, racionales, emocionales y sociales.

De acuerdo con la definición de marketing de la American Marketing Association (2007), la dirección de relaciones en el ámbito interactivo implica desarrollar una gestión de excelencia en contenidos y una estrategia de vínculos. El objetivo es incrementar la satisfacción del cliente mediante aspectos que aporten calidad en el proceso de navegación y mejora en dichas relaciones. 


\section{La gestión de eBranding}

La gestión del eBranding o Digital Branding en una empresa implica la toma de decisiones en los ámbitos estratégico, táctico y técnico (ver tabla II). En el ámbito estratégico se analiza la proposición motivante de la marca que permita desarrollarla en sus aspectos funcionales, emocionales y sociales en Internet; en el ámbito táctico, se desarrollan estrategias de marca on line que generan una experiencia única en el usuario; por último, en el ámbito técnico, se implantan técnicas de capacitación y fidelización online: las importantes sumas de dinero invertido en captación se pierden si no se han establecido señales comprensibles en la navegación, servicios básicos al usuario, una garantía de velocidad de flujo y un diseño visual atractivo.

\section{1. Ámbito estratégico}

En Internet, el desarrollo del Brand Essence Building (Young and Rubicam) debe generar una experiencia óptima que haga del espacio web una comunidad que aporte valor significativo a la marca y fidelice al consumidor en sus aspectos funcionales, emocionales y sociales.

\section{2. Ámbito táctico}

Existen diversas decisiones de marcas en línea que deben analizarse desde un punto de vista táctico. Internet requiere estrategias más complejas para conseguir posicionar la marca como preferente y única en la mente de los consumidores, ya que este tiene a un solo clic toda la oferta de productos del mundo. Las alternativas para establecer las marcas en línea son (Chaffey, D.; Mayer, R.; Johnston, K.; Ellis-Chadwich, F., 2003):

- $\quad$ Extensión de la marca tradicional. Marcas bien establecidas en el entorno off line que también se utilizan on line (Ford).

- $\quad$ Extensión de una variante de la marca. Versión ligeramente modificada de la marca para el sitio web (Expansión Directo).

- $\quad$ Alianza con una marca digital o co-branding. Acuerdos entre marcas para desarrollar actividades de marketing de manera conjunta. Con esta estrategia, se refuerza la imagen de ambas (Terra con Lycos).

- Creación de una nueva marca. Es la opción cuando se quiere llegar a segmentos diferentes de aquellos a los que se orienta en los entornos off line. El portal Go mantiene un nombre de marca diferente a Walt Disney, empresa a la que pertenece. 
También se puede optar por una estrategia de branding en la que el dominio con el nombre de la marca (www.cocacola.es) se convierta en la plataforma de promociones, comunidad virtual o portal de refuerzo de posicionamiento de marca. Y por otra parte, se crea un nombre de dominio ad hoc en el que se publica la información corporativa de la compañía (www.conocecocacola.com).

\section{3. Ámbito técnico}

Es necesario, asimismo, desarrollar técnicas de captación y de fidelización web para generar marca y presencia en la Red, dada la tendencia mayoritaria al abandono del proceso de compras tras haber llegado al sitio web. Según Alet (2007), las técnicas de captación on line deben usarse empleando un mix estratégico, siendo algunas de ellas la gestión del nombre del dominio, el posicionamiento natural y publicitario en buscadores, los vínculos con otros sitios, las campañas de comunicación off line, las conferencias y relaciones con prensa digital y websites, las campañas on line: banners, e-mail, notas prensa, links, patrocinios, etc., los programas de afiliados, el e-mail marketing y el marketing viral, la optimización en redes sociales y la presencia en blogs.

La conversión de visitante en usuario (portal) o comprador (comercio electrónico) depende de factores como la usabilidad ( facilidad de uso y navegación intuitiva), el contenido valioso (detalle de información, actualidad y utilidad, exclusividad, entretenimiento, asesoramiento y comunidad), la imagen atractiva, la personalización y la comunidad de marca.

La gestión del eBranding, por último, conlleva analizar al usuario, estudiar las opiniones de los consumidores y reflexionar sobre los comentarios de los receptores, destinatarios que abandonan su rol de simple "receptor" para convertirse en emisores de la propia marca de la empresa gracias a la tecnología en Internet y a los nuevos servicios de la web 2.0. Blog Pulse de Nielsen (www.blogpulse.com), por ejemplo, mide gráficamente cuántos comentarios se realizan sobre una marca y los compara con lo que se dice de la competencia.

\section{Conclusiones}

Gestionar el eBranding debe ir más allá de tener presencia en la Red con un logo más o menos adaptado a una interfaz digital. Actualmente se desarrollan nuevas variables que definen el cambio en el sector del marketing, ya que el control está en manos del consumidor. 
Los sistemas de control de comunicación no pueden medir únicamente impresiones, sino también intercambios. La transparencia de los procesos cobra importancia en la medida en que la voz del usuario pasa a ser la voz de una marca. Se trata, por tanto, de crear comunicaciones multiplataforma que conecten con el usuario cuando quiera y donde quiera. Es la era del eBranding o del Branding on demand.

El principal reto para las marcas en la era del branding 2.0 es cómo llegar a las grandes audiencias, para lo que es necesario buscar conexiones, desarrollar experiencias ricas para el usuario (Schmitt, 2000), conseguir la máxima cuota de pantalla, centrarse en el share of customer, por la creatividad, perseguir el ROI con search marketing y afiliación, conectar fansumers, desarrollar el ESP o Emotional Selling Proposition (Frazer, 1983), actuar en "glocal” y, por último, interactuar con mensajes crossmedia.

El modelo que se propone se apoya en la búsqueda de satisfacción del usuario online y la reputación corporativa y, a partir de modelos clásicos de capital de marca, identifica los elementos clave de la gestión de contenidos y de intangibles en Internet. En este nuevo soporte, el proceso de creación de valor posee especiales características ya que la gestión de marcas on line requiere de un proceso de branding específico y de una aportación de beneficios no solo racionales, sino también emocionales y sociales.

La gestión del ebranding abarca los ámbitos estratégico, táctico y técnico e implica la toma de decisiones relativas a la creación de experiencias óptimas, al posicionamiento y la captación y la fidelización que conducen a la compra. Es preciso, por tanto, formar profesionales capaces de diseñar y articular los elementos tangibles e intangibles del digital branding, para dar respuesta a las nuevas necesidades del sector.

\section{Referencias bibliográficas}

Aaker, D. (1991): Managing Brand Equity, New York: Free Press.

- (1996): Construir marcas poderosas, Barcelona: Gestión 2000.

Alet, J. (2007): Marketing directo e interactivo, Barcelona: ESIC.

Alloza, A. (2001): “Gestión estratégica de la marca” en Informe Anual de la Publicidad y el Corporate en España y Latinoamérica, Madrid: Pirámide.

American Marketing Association (2007): “Definition of Marketing” en Marketing Power (on line). Disponible en http://www.marketingpower.com

Bassat, L. (2008): Conferencia de Luis Bassat en “Los Desayunos IAB Spain”, Madrid.

Berners-Lee, T. (2000): Tejiendo la red, Siglo XXI de España. Madrid. 
Chaffey, D.; Mayer, R.; Johnston, K.; Ellis-Chadwich, F. (2003): “Internet Marketing. Strategy, Implementation and Practice”, Harlow: Prentice Hall.

Csikszentmihalyi, M. (1998): Creatividad. El fluir y la psicología del descubrimiento y la invención, Barcelona: Paidós.

Estudio General de Medios (2009): Audiencia de Internet Febrero - Marzo, Madrid.

Frazer, C. (1983): "Creative Strategy: a management perspective", en Journal of Advertising, vol. 12, n. 4.

Kotler, P., Lane, K. (2006): Dirección de marketing, Madrid: Pearson.

Levine, R.; Locke, C.; Searls D.; y Weinberger, D. (2000): The Cluetrain Manifiesto, Perseus Book.

Moliné, M., (2005): "Reinwwwentando la publicidad" (on line). Artículo disponible en Internet en: http://www.molineconsulting.com/index-reinventando.htm.

Reeves, R. (1964): La realidad en la publicidad, Madrid: Severo-Ochoa.

Ries, A. y Ries, L. (2000): Las 11 leyes inmutables de la marca en Internet, Madrid: McGraw-Hill.

Schmitt, B. H. (2000): Experiential Marketing, Bilbao: Deusto.

Vallet Saavedra, G. (2005): eBranding. La creación de marca digital en la era de la conectividad, Director de tesis: José Mª Ricarte, Universidad Autónoma de Barcelona, Departamento de Comunicación Audiovisual y Publicidad. 